\title{
Weather Forecasting
}

\author{
By Dr. G. C. Simpson, c.B., O.B.E., F.R.S., Director of the Meteorological Office
}

\section{$\mathrm{T}$} HE most important advance in weather forecasting during the last twenty-five years owed its origin to the War ; but unlike so many other war-time advances, it was not made in connexion with the prosecution of war.

Twenty-five years ago, the method of weather forecasting, developed and described by Abercromby twenty-five years earlier, had undergone very little change. Synoptic charts were prepared and isobars drawn to indicate the pressure distribution. Seven main types of isobars were recognised, and Abercromby had described in great detail what kind of weather is usually associated with each. To take one example: the most common and most important pressure distribution is the cyclonic depression, and Abercromby prepared a diagram showing the weather association with this type of pressure distribution. He drew two ovals, one inside the other, to indicate the typical shape of the isobars; a long arrow was drawn along the major axis to indicate the line of movement of the depression, and the space within the oval was filled with descriptions of the weather which occur in the different parts. In the front of the depression Pale Moon and Watery Sun are indicated; in the right fore quadrant, Muggy and Gloomy are entered; and near the centre Dirty Sky and Driving Rain are noted. The forecaster having found a depression on his chart and determined the direction in which it was moving, would issue his forecasts on the assumption that places over which the depression would pass would experience the weather scheduled by Abercromby.

Abercromby's descriptions of the weather associated with each type of isobar were well done, and a very useful percentage of correct forecasts could be made; but the method was, by its very nature, unsatisfactory; for only average conditions could be forecast, and one knew from bitter experience that very large variations from type were possible.

Meteorologists were well aware that better forecasts could not be made on such a system, and that it was necessary to learn more about the physics of the atmosphere, and to take the upper atmosphere into account. For a number of years a very active investigation of the upper atmosphere had been carried on and important results had been obtained: the stratosphere had been discovered and many interesting statistical relationships between the conditions at different heights had been computed; but none of them appeared to be of much use in practical forecasting, and in any event no method was then known by which information regarding upper air conditions could be obtained sufficiently rapidly to be of use in preparing a forecast for the next twenty-four hours.

Napier Shaw and Lempfert had tackled the problem in another way. They had investigated what happens in a depression by following the path of the air, and so determining where it came from and where it went. The result was a classical paper on the "Life History of Surface Air Currents", and Shaw in a subsequent paper came very near to making the discovery which ten years later was to have such a revolutionary effect; but all this work, in spite of its great theoretical value, had produced very little to help the forecaster, and when the War broke out, Abercromby's empirical method was still the basis of all weather forecasting.

In Norway, although far removed from the seat of War, it was practically impossible to carry on the State Meteorological Service during 1914-18 owing to the total cessation of meteorological information from the outside world. Under the guidance of Prof. V. Bjerknes, the meteorologists decided to try to compensate for the loss of the foreign observations by increasing the observation posts within their own country. Prof. Bjerknes himself was a mathematician and not a forecaster ; but there were two young men, one his own son J. Bjerknes, and the other H. Solberg, who took charge of the practical work. The number of telegraphic reporting stations in the southern part of the country was increased from eight to about ninety. The observing stations were so close together that it was almost possible to follow individual masses of air from one to another.

When, by the aid of this close network of stations, the stream lines of the air were plotted, it was sometimes found that a broad and well-marked stream of air would seem to come to a sudden end. A long line could be drawn on the chart marking where the stream of air came to an end, and it was then found that beyond this line there was a strip of country, two or three hundred kilometres wide, over which rain was falling through a current of colder air flowing in a different direction. Further investigation, including a study of the temperature on each side of the line, 
showed what was really happening. In all such cases a stream of warm air had met a mass of cold air and been forced to ride over it, the cold air forming a wedge up which the warm air ascended. When air is forced to ascend in the atmosphere in this way it is cooled and precipitation takes place, thus accounting for the rain beyond the line marking where the ascent began. Frequently these broad bands of rain can be traced for thousands of kilometres across country.

On other occasions it was found that a broad stream of cold air would end as abruptly against a mass of warm air ; but in this case the rain band would be much narrower than in the former case and would be situated before instead of beyond the line of junction. The explanation was simple. In this case the moving air, being colder than the air against which it was impinging, could not ride over it, but must travel underneath. In effect, a wedge of cold air pushed its way under a mass of warm air and lifted it upwards over itself. The rain due to the ascending warm air fell through the wedge, and therefore appeared at the ground in front of the line of junction between the two air masses.

It was war-time, so it was natural to liken the process to that of advancing armies and to call the lines of junction between the masses of the air which extended for so many miles across the country 'fronts'. A front at which warm air advanced against cold air and was forced upwards was called a 'warm front'; while one at which cold air pushed its way under warm air was called a 'cold front'. There was nothing very revolutionary in the idea of one current of air overriding another without mixing, the two currents remaining separated at a surface where there was a discontinuity of temperature and air motion. Helmholtz had investigated the conditions in which such surfaces of discontinuity could exist, Margules had worked out the formula for calculating the equilibrium-inclination of such surfaces and Shaw and Lempfert had already recognised them on their synoptic charts. It was, however, the next step made by the Norwegians which was so important; for they showed that warm and cold fronts are an integral part of the formation and development of cyclonic depressions. A depression forms on a surface of discontinuity which, as the depression develops, becomes differentiated into a warm front and a cold front meeting at the centre; while the precipitation is chiefly associated with these fronts.

Thus at last a physical structure had been put into a depression, and Abercromby's distribution of weather had been brought into an ordered relationship with processes taking place in the upper atmosphere. From then on, the forecaster had a new tool ealled 'frontal analysis' with which to work. He now searches his synoptic chart for fronts and surfaces of discontinuity, and when he finds them he knows what weather to expect. When a front has once been located, the surface of discontinuity associated with it can be followed by characteristic cloud formation and rain bands for a very long time. In this way the forecaster is able to foretell even minor changes of weather and to fix with considerable accuracy the time at which the changes will take place. This is of inestimable value in connexion with forecasting for aviation.

Fronts and surfaces of discontinuity are due to the existence of different masses of air which are brought into contact; and it is now necessary to say a few words about 'air masses'. Air which remains for any length of time in one locality takes up the temperature and humidity characteristic of that locality; thus the chief characteristic of the air in polar regions is low temperature, while that of air in tropical regions is high temperature. When air from polar or tropical regions moves into mid-latitudes it does not immediately take up new characteristics; but it retains those of its place of origin for a relatively long time, and it is possible, especially when upper air observations are available, to determine the origin of the air over very large areas.

The two main types of air masses are polar and tropical, but polar air may come from a sea area or from a continental area, and although in both cases the air will be cold it will have different characteristics of humidity and lapse rate. In this way 'maritime polar air' and 'continental polar air' have come to be recognised. 'Mass analysis' is now an important branch of 'frontal analysis', and many different types of air masses are specified by different names. Each of these air masses has its own physical properties which are important from a weather point of view. Polar air is generally clear, with good visibility; maritime polar air is very unstable owing to the warming of its lower layers when passing over the relatively warm sea, and in it showers and squalls easily develop; tropical air is generally very stable, and showers do not occur in it, but it is the tendency of this air to override cold air which, aided by its high humidity, gives steady rain; the visibility is generally poor in tropical air. The forecaster has therefore come to examine more closely the air masses, first because of their intrinsic characteristics, and secondly because it is at the junction between air masses of different origin that surfaces of discontinuity occur.

It has already been mentioned that, at the 
outbreak of War, upper air observations were not available, and if they had been forecasters would not have known what to do with them. The conditions are very different now; for aeroplanes have made it possible to get the information quickly, and our new knowledge of the part played by air masses and surfaces of discontinuity makes all information from the upper air of great importance. Practically all countries now use aeroplanes for upper air observations as part of their forecasting services.

There can be no doubt that during the last twenty-five years the forecaster has made great steps forward and forecasting is slowly being changed from an art, in which experience and intuition played the predominating part, into a science in which cause and effect are recognised and taken into account.

\section{Conceptions of Man's Ancestry}

\section{By Sir Arthur Keith, F.R.s., lately Hunterian Professor of the Royal College of Surgeons}

$\mathrm{W}$ HEN King George came to the throne, anthropologists had begun to realise that man's family tree was to prove a much more complicated thing than was anticipated. The discoveries made in France between 1907 and 1909 compelled them to abandon the idea that mankind had been evolved by a single progressive series of stages which, beginning in an ape-like stage, ended in the races of modern humanity. They had to give up the singlestemmed family tree and substitute for it one with rather a shrub-like outline. Most of them regarded Neanderthal man as a stage in the evolution of modern man. The discoveries made in France, at the date just mentioned, proved that this could not be so, and that Neanderthal man, after occupying Europe for a large part of the pleistocene period, had been suddenly replaced by representatives of modern or neanthropic man. Whether the neanthropic races, which replaced the Neanderthal inhabitants of Europe, came from Africa or from Asia still awaits determination. Neanderthal man could not be fitted into any single-stemmed scheme; he represented the end twig of a dead branch. Since 1910, several more dead branches have been discovered and fitted into provisional reconstructions of man's family tree.

At the beginning of this period another idea relating to the antiquity of modern man was being much discussed. Was it possible that human beings, exactly similar to modern Europeans in details of structure, could have been in existence in mid-pleistocene times, when the $100 \mathrm{ft}$. terrace of the Thames was being laid down and the large Chelles hand-axes were being fashioned? There were many-including the writer-who answered this question in the affirmative. The case we relied on was that of Galley Hill, near Gravesend, but discoveries of a similar kind had also been reported from France, from Italy and from North America. Galley Hill man lay under mid-pleistocene strata which were apparently unbroken. The discoveries which have been made during the past twenty-five years have not supported the Galley Hillites; the opposite has been the case. Most anthropologists now hold that the human body is so unstable in its constitution-and always has been so unstable-that it cannot continue the same over a long period of time, but must change. Hence we are all inclined now, in the case of Galley Hill and all discoveries of a similar kind, to reject the geological evidence rather than believe that the human body can exist for a long period of time-say, 50,000 years-and remain unchanged.

Our knowledge of Neanderthal man has been greatly extended. In 1911 Marcelin Boule pub. lished his classical monograph on the anatomy of La Chapelle man-perhaps the best known of Neanderthal specimens. The earliest or oldest trace of the Neanderthal phylum is represented by the Heidelberg mandible, which was discovered in 1907. In spite of a prolonged search, this is still the sole trace we have of the ancestry of Neanderthal man in the earlier part of the pleistocene period. Two discoveries, however, have revealed stages which fill up in some degree the interval between the early Heidelberg and late La Chapelle stages in the evolution of the Neanderthal type. One of these was made in the travertine quarry at Ehringsdorf, near Weimar, in 1925 ; the other was made in a gravel pit, just outside Rome, in 1929. At Ehringsdorf and at Rome, the Neanderthal skulls were embedded in deposits formed during the long temperate interval which preceded the last glacial period. The Ehringsdorf man was big-brained and had certain characters more reminiscent of modern (neanthropic) man than the later Neanderthal specimens. There are reasons for linking the discovery at Ehringsdorf with that made at Krapina, Croatia, in 1906. A discovery made in 1924 revealed the fossil remains of Neanderthal man in the Crimea, thus carrying the distribution of this extinct type almost into Asia. 